\title{
Assessment of factors influencing the stability of Ukrainian export based on the fractal analysis
}

\author{
Dmytro Kainara ${ }^{1, *}$ and Iuliia Kaliuzhna ${ }^{1, * *}$ \\ ${ }^{1}$ Zaporizhzhia National University, 66 Zhukovsky Str., Zaporizhzhia, 69063, Ukraine
}

\begin{abstract}
The article considered the assessment of the sustainability of the export flow of Ukraine. It was determined that the markets of Slovakia, the Russian Federation, Germany, Poland and Lithuania possess longterm memory. Also, the main factors that affect the sustainability of export have been analyzed. Among cultural factors, a weak correlation was demonstrated by Long Term Orientation, Indulgence and Power Distance according to the Geert Hofstede method. At the same time, the cultural patterns according to the S. H. Schwartz method did not show a correlation with the long-term memory of product export. On the stability of the export flow, the role of the linguistic distance and the factor of the diaspora presence have been assessed. It was proved that the gravitational effect has the greatest impact on the stability of export; Power Distance, linguistic distance and the factor of the diaspora presence have the negligible impact as well
\end{abstract}

\section{Introduction}

International trade in its nature is a self-organizing system under the influence of international politics, the politics of national states, the politics of international organizations, the politics of individual market entities, etc.

The influence of the international trade entities forms the cycles and trends in the market. Thus, even at first sight, the unstable markets, with a high level of price volatility and a wide range of trade volumes, in fact, may have a clear trade structure, which is subject to the seasonality factors, economic cycles within the country and international policies of their states.

To estimate the factor of a long-term memory, the market uses fractal analysis, which allows one to find patterns that cannot be estimated by the traditional statistical methods. And so that, to understand the trends that actually exist on the market, as well as factors that have a latent effect on the export of the products, which forms the relevance of this work.

\section{Methodology}

Fractal analysis is used to assess the stability of export flows taking into account the influence of cyclical factors. This method was founded by H. E. Hurst [1] and based by $\mathrm{R} / \mathrm{S}$ analysis technique. $\mathrm{R} / \mathrm{S}$ analysis reveals patterns to detect regularities and long-term memory in conditions where traditional methods do not allow it.

Using a temporal analysis approach, B. Mandelbrot [2], and later E. Peters [3] discovered the effect of longterm memory in the stock markets. The stock market has been proven to have a long-term memory.

\footnotetext{
*e-mail: Kainara1992@gmail.com

**e-mail: kalyuzhnaya.ju@gmail.com
}

E. Peters identified 3 types of markets, depending on the indicator that the Hurst coefficient took [3]:

- $0 \leq H<0.5$ - fractal market with an antipersistent series - these markets are characterized by unstable dynamics and the tendency of the indicator to the "average" value;

- $H=0.5-$ efficient market (EMH), where prices are set according to the theory of E. F. Fama;

- $0.5>H \geq 1$ - fractal market with a persistent series. These markets are characterized by a stable trend and long-term memory.

Since the volume of sales depends on the price of the product, this indicator can be used to analyze the level of stability in the market.

Data for R/S analysis was taken from UN Comtrade Database [4]. The sampling interval for the analysis was from January 01, 2010 to December 31, 2020: monthly indicators. This sample was determined due to the fact that the average economic cycle in the world lasts 10 years. However, since at the time of submitting the work to the editorial office, there are no data for October 01, 2020 December 31, 2020, they were predicted using a simple moving average. Upon that, the deviation of the Hurst coefficient from the real one will not exceed $1 \%$, which will insignificantly affect the results of the work.

For R/S analysis the following algorithm was used [5]:

1. Conversion of the time series in the logarithmic number:

$$
t_{i}=\ln \frac{x_{i}}{x_{i-1}}, i=2 \ldots n
$$

2. Finding the divisor for dividing a logarithmic series into $k$ intervals with $b$ number of elements in each interval. 
Table 1. The results of assessing the export flow to Ukraine's main trading partners

\begin{tabular}{|c|c|}
\hline Country & Hurst coefficient \\
\hline \multicolumn{2}{|c|}{ Fractal market with persistence of trends } \\
\hline Slovak Republic & 0,9427 \\
\hline Russian Federation & 0,9422 \\
\hline Germany & 0,8939 \\
\hline Poland & 0,8593 \\
\hline Lithuania & 0,8537 \\
\hline Belarus & 0,8316 \\
\hline United States & 0,8303 \\
\hline Romania & 0,8067 \\
\hline Georgia & 0,7641 \\
\hline Moldova & 0,7371 \\
\hline Bulgaria & 0,7327 \\
\hline Hungary & 0,7327 \\
\hline Chile & 0,709 \\
\hline Brazil & 0,6968 \\
\hline Azerbaijan & 0,6949 \\
\hline Iran, Islamic Republic & 0,6906 \\
\hline Sweden & 0,6828 \\
\hline Italy & 0,6795 \\
\hline Egypt, Arab Republic & 0,6762 \\
\hline Spain & 0,6761 \\
\hline France & 0,6739 \\
\hline Turkey & 0,6725 \\
\hline Armenia & 0,6587 \\
\hline China & 0,6479 \\
\hline Algeria & 0,6271 \\
\hline Canada & 0,6266 \\
\hline Austria & 0,6238 \\
\hline Kazakhstan & 0,612 \\
\hline \multicolumn{2}{|c|}{ Effective market (EMH) } \\
\hline Jordan & 0,5984 \\
\hline Israel & 0,5979 \\
\hline United Kingdom & 0,5927 \\
\hline Albania & 0,5909 \\
\hline Ireland & 0,5809 \\
\hline Japan & 0,5793 \\
\hline Mexico & 0,5742 \\
\hline Denmark & 0,5705 \\
\hline Greece & 0,5683 \\
\hline Estonia & 0,5672 \\
\hline Finland & 0,5619 \\
\hline Portugal & 0,552 \\
\hline New Zealand & 0,535 \\
\hline Latvia & 0,4946 \\
\hline \multicolumn{2}{|c|}{ Fractal market with anti-persistence of trends } \\
\hline Argentina & 0,4348 \\
\hline Australia & 0,4197 \\
\hline Peru & 0,4106 \\
\hline South Africa & 0,4078 \\
\hline
\end{tabular}

3. Finding the average value of the interval:

$$
\bar{S}_{i}=\frac{1}{b} \sum_{i=1}^{b} t_{i}
$$

Table 2. The gravity effect between Ukraine and main trading partners

\begin{tabular}{|c|c|}
\hline Country & Gravity coefficient \\
\hline Albania & 34,8575 \\
\hline Algeria & 35,8521 \\
\hline Argentina & 33,654 \\
\hline Armenia & 34,3709 \\
\hline Australia & 34,5056 \\
\hline Austria & 38,6596 \\
\hline Azerbaijan & 35,2912 \\
\hline Belarus & 38,4896 \\
\hline Brazil & 35,469 \\
\hline Bulgaria & 36,8507 \\
\hline Canada & 36,1735 \\
\hline Chile & 33,0968 \\
\hline China & 38,5091 \\
\hline Denmark & 37,9589 \\
\hline Egypt, Arab Republic & 36,7419 \\
\hline Estonia & 35,9915 \\
\hline Finland & 38,009 \\
\hline France & 39,1631 \\
\hline Georgia & 34,7596 \\
\hline Germany & 40,554 \\
\hline Greece & 37,2181 \\
\hline Hungary & 37,9761 \\
\hline Ireland & 36,7848 \\
\hline Israel & 37,1875 \\
\hline Italy & 39,2376 \\
\hline Japan & 36,9915 \\
\hline Jordan & 34,9293 \\
\hline Kazakhstan & 35,7818 \\
\hline Latvia & 36,5566 \\
\hline Lithuania & 37,7291 \\
\hline Mexico & 35,0504 \\
\hline Moldova & 36,9715 \\
\hline New Zealand & 32,3209 \\
\hline Peru & 33,0756 \\
\hline Poland & 39,5154 \\
\hline Portugal & 35,2591 \\
\hline Romania & 37,9941 \\
\hline Russian Federation & 40,5115 \\
\hline Slovak Republic & 37,3133 \\
\hline South Africa & 34,0342 \\
\hline Spain & 37,8024 \\
\hline Sweden & 38,4725 \\
\hline Turkey & 38,9623 \\
\hline United Kingdom & 39,0992 \\
\hline United States & 38,522 \\
\hline
\end{tabular}

4. Finding the accumulated deviation from the average value for each value and series:

$$
X_{i, k}=\sum_{i=1}^{b}\left(t_{i}-\bar{t}_{i}\right)
$$

5. Calculating the range for each interval:

$$
R_{k}=\max \left(X_{i, k}\right)-\min \left(X_{i, k}\right)
$$


Table 3. Correlation analysis of the impact of cultural factors on export sustainability

\begin{tabular}{|c|c|c|c|c|c|c|c|c|}
\hline & $\begin{array}{l}\text { Hurst co- } \\
\text { efficient }\end{array}$ & $\begin{array}{l}\text { Power } \\
\text { Distance }\end{array}$ & Individualism & Masculitinity & $\begin{array}{l}\text { Uncertainty } \\
\text { Avoidanance }\end{array}$ & $\begin{array}{l}\text { Long Term } \\
\text { Orientation }\end{array}$ & Indulgence & $\begin{array}{l}\text { Gravity } \\
\text { Effect }\end{array}$ \\
\hline Hurst coefficient & 1 & & & & & & & \\
\hline Power Distance & $-0,333$ & 1 & & & & & & \\
\hline Individualism & $-0,111$ & 0,75 & 1 & & & & & \\
\hline Masculitinity & 0,039 & 0,1 & 0,3 & 1 & & & & \\
\hline $\begin{array}{l}\text { Uncertainty } \\
\text { Avoidanance }\end{array}$ & $-0,207$ & 0,66 & 0,6 & 0,2 & 1 & & & \\
\hline $\begin{array}{l}\text { Long Term Orien- } \\
\text { tation }\end{array}$ & $-0,451$ & 0,24 & 0,1 & $-0,1$ & 0,1 & 1 & & \\
\hline Indulgence & $-0,394$ & 0,5 & 0,4 & 0,16 & 0,5 & 0,6 & 1 & \\
\hline Gravity Effect & 0,594 & 0,1 & 0,3 & 0,1 & 0,1 & $-0,4$ & $-0,2$ & 1 \\
\hline
\end{tabular}

6. Calculating the standard deviation for each interval:

$$
S_{k}=\sqrt{\frac{\sum_{i=1}^{b}\left(t_{i}-\overline{t_{i}}\right)^{2}}{b-1}}
$$

7. Finding the normalized range for the interval:

$$
R / S_{k}=\frac{R_{k}}{S_{k}}
$$

8. Finding the average value of the normalized range over all intervals:

$$
R / S=\frac{1}{k} \sum_{i=1}^{k} R_{i}
$$

9. Calculating the standard error:

$$
V=\frac{R / S}{\sqrt{b}}
$$

10. Doing subsequent iterations of the algorithm increasing the number of $b$ values in intervals.

Selecting the $b$ values was carried out according to the principle: 3 months (quarterly cycle of companies), 6 months (half-year cycle of companies), 12 months (annual cycle of companies), 24 months (two-year cycle), 40 months (average duration of the economic cycle in the Ukrainian economy).

\section{Literature review}

Today, the fractal analysis is used mainly for analyzing the characteristics of the stock market and predicting price trends [6-9] and less often for forecasting the market [1014]. First of all, it is necessary to highlight the work of T. Ikeda [6], who conducted the fractal analysis of the main stock markets of the world and proved the presence of fractality in them. This is the opinion of R. F. Mulligan in his work [7].

In the work of M. Frezza, S. Bianchi and A. Pianese [15], the authors use the fractal analysis capabilities to track propagation waves of the COVID-19 crisis. In the work of M. Karpiarz, P. Fronczak and A. Fronczak [16], the fractal analysis was used to interpret the distance coefficient in the distance of the gravity model.

However, scientists practically did not use the fractal analysis to assess the export flow, which significantly limits the understanding of the foreign trade trends.

\section{Impact and sustainability of export flows}

The analysis of trends in the international trade in Ukraine shows that in 2019 the main partner in the export of products is the European Union, China, Russia, Turkey. The share of the Russian Federation in the export of products has been steadily decreasing over the past 6 years, which may indicate, at first sight, the instability of trade between the countries. Herewith, the trade with the EU and the PRC in the initial analysis of the data indicates stable dynamics [4].

The results of assessing the export flow using the R/S analysis are shown in table 1 . The source of information is the UN Comtrade Database [4].

Also, despite a significant decrease in trade between the Russian Federation and Ukraine, the trade relations between the countries remain significant. The reason for this is the preservation of economic relationships that have existed since the USSR, cultural closeness, high gravitational influence of the Russian economy and low language barriers.

Further, it is worth noting the almost identical Hurst coefficient for Poland and Lithuania. This may indicate the preservation of the relationships between the countries, which has existed since the times of the Polish-Lithuanian Commonwealth. The high Hurst coefficient for Germany can be explained by the gravitational influence of the economy on Ukraine.

In the international trade, the gravitational effect lies in the hypothesis that trade volumes depend on the level of their GDP and are inversely proportional to the distance between the countries. To assess the gravitational effect between the given countries, a modified J. Tinbergen formula was taken [17]:

$$
M_{i j}=\log \frac{Y_{j} \cdot Y_{i}}{D_{i j}^{2}}
$$

where $M_{i j}$ - attraction of two countries, 
Table 4. Assessment of linguistic distance and diaspora factor

\begin{tabular}{|c|c|c|c|}
\hline Country & $\begin{array}{l}\text { Level of } \\
\text { English } \\
\text { knowledge } \\
{[23]}\end{array}$ & $\begin{array}{l}\text { Diaspora } \\
\text { factor } \\
{[24]}\end{array}$ & Total \\
\hline Australia & 1 & 0 & 1 \\
\hline Austria & 0,623 & 0 & 0,623 \\
\hline Azerbaijan & 0,432 & 0,5 & 1,932 \\
\hline Argentina & 0,566 & 0 & 0,566 \\
\hline Armenia & 0,494 & 0,5 & 1,994 \\
\hline Belarus & 0,513 & 0,5 & 2,013 \\
\hline Bulgaria & 0,579 & 0 & 1,079 \\
\hline Brazil & 0,49 & 0,5 & 0,99 \\
\hline United Kingdom & 1 & 0 & 1 \\
\hline Hungary & 0,598 & 0,5 & 1,098 \\
\hline Germany & 0,616 & 0,5 & 1,116 \\
\hline Greece & 0,578 & 0 & 0,578 \\
\hline Georgia & 0,503 & 0,5 & 1,003 \\
\hline Egypt, Arab Republic & 0,437 & 0 & 0,437 \\
\hline Ireland & 1 & 0 & 1 \\
\hline Spain & 0,537 & 0,5 & 1,037 \\
\hline Italy & 0,547 & 0,5 & 1,047 \\
\hline Kazakhstan & 0,412 & 0,5 & 1,912 \\
\hline Canada & 1 & 0,5 & 1,5 \\
\hline China & 0,52 & 0 & 0,52 \\
\hline Latvia & 0,555 & 0,5 & 2,055 \\
\hline Lithuania & 0,57 & 0,5 & 2,07 \\
\hline Moldova & 0,589 & 0,75 & 2,339 \\
\hline Poland & 0,596 & 0,75 & 1,846 \\
\hline Portugal & 0,618 & 0,5 & 1,118 \\
\hline Russian Federation & 0,512 & 0,75 & 2,262 \\
\hline Romania & 0,589 & 0,5 & 1,089 \\
\hline Slovak Republic & 0,577 & 0,5 & 1,577 \\
\hline United States & 1 & 0,5 & 1,5 \\
\hline Turkey & 0,465 & 0 & 0,465 \\
\hline France & 0,559 & 0 & 0,559 \\
\hline Sweden & 0,625 & 0 & 0,625 \\
\hline Estonia & 0,566 & 0,5 & 2,066 \\
\hline South Africa & 0,607 & 0 & 0,607 \\
\hline Japan & 0,487 & 0 & 0,487 \\
\hline Finland & 0,613 & 0 & 0,613 \\
\hline Albania & 0,445 & 0 & 0,445 \\
\hline Algeria & 0,442 & 0 & 0,442 \\
\hline Denmark & 0,632 & 0 & 0,632 \\
\hline Chile & 0,532 & 0 & 0,532 \\
\hline Mexico & 0,440 & 0 & 0,440 \\
\hline Peru & 0,482 & 0 & 0,482 \\
\hline New Zealand & 1 & 0 & 1 \\
\hline Jordan & 0,456 & 0 & 0,456 \\
\hline
\end{tabular}

$Y_{j}, Y_{i}-\mathrm{GDP}$ of the countries $i$ and $j$,

$D_{i j}^{2}$ - distance between the capitals of the countries.

The results of the gravitational effect assessment are shown in table 2. The source of information is the World bank database [18] and the Distance database [19].

Germany and the Russian Federation have the greatest gravitational effect on the Ukrainian economy. It is also worth noting the high gravitational influence of other EU countries on the economy of Ukraine, primarily France, Poland and Sweden. At the same time, the United States of America, although locates at a considerable distance from Ukraine, has an equal comparable to neighboring Belarus.

The second factor that affects the long-term memory of product exports is cultural factors. These include both cultural patterns and language barriers, as well as the presence of a diaspora in the partner country.

G. Hofstede [20] and S. H. Schwartz [21] indicators will be used to assess the cultural barriers. To assess the cultural difference between the countries, it is necessary to calculate the difference between the corresponding indicator for Ukraine and the partner country:

$$
C D_{i j}=\left|C H_{i}-C H_{j}\right|,
$$

where $C D_{i j}$ - cultural distance between the countries $i$ and j;

$\mathrm{CH}_{i}$ and $\mathrm{CH}_{j}-\mathrm{G}$. Hofstede or S. H. Schwartz indicator for countries $i$ and $j$.

The correlation analysis for indicators of gravity effect and cultural distance is shown in table 3 .

The average correlation effect between the stability of export and the gravitational effect of 0,5939, as well as a weak influence between the Hurst coefficient and Long Term Orientation, Indulgence and Power Distance is preserved.

The presence of a negative correlation between individual cultural patterns confirms the thesis about the influence of cultural distance on the long-term memory of product exports. At the same time, the pattern of long-term "Long Term Orientation and Indulgence" has the greatest influence, which indicates the best interaction in export transactions between people of similar nature. As for the weak inverse correlation of Power Distance and Hurst coefficient, we can say that company employees prefer to work more with countries with similar governments and distance from society.

At this, there is no correlation between the Hurst coefficient and S. H. Schwartz indicators. Linguistic factors and factors of the presence of a common diaspora also affect the stability of export. Let's consider this factor. As a methodology for assessing the impact of linguistic distance and the presence of a diaspora, we use the approach proposed by L. Vlasenko [22].

The factor of knowledge of the English language was taken as a factor in assessing the linguistic distance. The EF EPI rating was used to assess the level of knowledge of the English language [23].

Table 5. Linguistic distance and diaspora factor correlation analysis

\begin{tabular}{lll}
\hline & Hurst coefficient & $\begin{array}{l}\text { Linguistic dis- } \\
\text { tance and di- } \\
\text { aspora factor }\end{array}$ \\
\hline $\begin{array}{l}\text { Hurst coefficient } \\
\begin{array}{l}\text { Linguistic } \\
\text { distance and } \\
\text { diaspora factor }\end{array}\end{array}$ & 0,460836 & 1 \\
\hline
\end{tabular}


Table 6. The results of the regression model

\begin{tabular}{lllllll}
\hline & Coefficient & Standard error & t-Statistic & P-Value & Lower 95\% & Upper 95\% \\
\hline Hurst coefficient & $-0,67428$ & 0,26512 & $-2,54331$ & 0,014951 & 0,033937 & 0,228792 \\
Gravity coefficient & 0,034611 & 0,00742 & 4,661742 & $3,46 \cdot 10^{-55}$ & $-1,21011$ & $-0,13845$ \\
Power distance & $-0,00152$ & 0,000632 & $-2,41061$ & 0,020613 & 0,019606 & 0,049617 \\
Linguistic distance and diaspora factor & 0,131365 & 0,048206 & $-0,0028$ & $-0,00025$ & & \\
\hline
\end{tabular}

Moreover, in the countries where knowledge of the language is native, the indicator equals to 1 . As for the diaspora, based on Ethnologue data [24] the indicator of the diaspora presence was assigned a value of 0 (in the $a b-$ sence of a significant common diaspora), in the presence of a significant common diaspora a value of 0,5 , and in the presence of very significant common diaspora a value of 0,75 .

The results of assessing the indicator of linguistic distance and the diaspora factor are shown in table 4 .

The results of the correlation analysis are shown in table 5 .

Thus, a correlation index of 0,46 indicates the presence of an average correlation between the linguistic distance and diaspora factor and with the Hurst coefficient. Consequently, the level of knowledge of the English language in a society affects the size of the cultural barriers that arise in trade. And in the context of globalization, an increase in the level of English proficiency in society will allow the formation of stable ties in trade, which will positively affect the trade flow.

Further, based on the factor of culture, gravitational impact, linguistic distance and diaspora, let's conduct a regression analysis to identify the level of influence of each of the indicators on the level of stability.

Thus, there is an average correlation between the gravity coefficient and the Hurst coefficient, the weak correlation between the Hurst coefficient and the Power Distance, and the linguistic distance and the diaspora factor. The results of a regression model building are shown in table 6 .

Thus, all indicators are statistically significant. And the given t-statistic values are above the critical value of 2,039 .

The indicators of the regression model quality are shown in table 7 .

Table 7. Quality indicators of the regression model

\begin{tabular}{ll}
\hline Indicator & Value \\
\hline Multiple R & 0,723433 \\
R Square & 0,523355 \\
Adjusted R Square & 0,487607 \\
Standard Error & 0,095665 \\
Fisher criterion & 14,63998263 \\
Approximation index & $14,64 \%$ \\
\hline
\end{tabular}

As a result, the data presented indicate the statistical significance of the regression model. In fact, the Fisher's criterion is higher than the critical value $(2,911)$. At the same time, the approximation indicator is $14,64 \%$, which indicates the high quality of the model. To assess the level of influence of factors on the Hurst coefficient, an elasticity analysis has been performed.

The results are shown in table 8 .

Table 8. The elasticity analysis

\begin{tabular}{ll}
\hline Indicator & $\begin{array}{l}\text { Level of } 1 \% \\
\text { variation }\end{array}$ \\
\hline Gravity factor & $1,846 \%$ \\
Power distance & $1,843 \%$ \\
Linguistic distance and diaspora factor & $0,194 \%$ \\
Other factors & $0,979 \%$ \\
\hline
\end{tabular}

Thus, the analysis showed that cultural factors have the same influence as the factors of gravitational influence on long-term memory in export shipments. At the same time, the linguistic distance and the factor of the presence of a diaspora in the country have an insignificant effect on long-term memory.

This suggests that Ukraine's export instead of economic factors and economic benefits is more susceptible primarily to personal connections and preferences of the management of firms and managers who are engaged in the foreign economic activity.

\section{Conclusion}

As a result of the conducted study, it was established, first of all, that Ukraine's export supplies to the main partner countries are subject to fractality, which indicates the presence of a long-term memory in the market. Exports to the Russian Federation are indicative, the share of which in the total export structure was significantly reduced after 2014. However, despite this, a large number of companies still supply their products to the Russian market and depend on the economic processes that are taking place in the Russian Federation. At the same time, a high level of a long-term memory of export trade is also observed with the EU countries and the USA.

In this case, the size of the country's GDP and the proximity of its location have the greatest influence on the level of fractality, which was calculated using the Gravity factor. An interesting result is the fact that cultural affinity between countries plays an almost identical role to that of the Gravity factor. At the same time, the presence of a diaspora, as well as the level of knowledge of the English language in society, has little effect on the level of a long-term memory.

This trend is more negative than positive. The high level of dependence on key partner countries with a similar culture indicates the inability of Ukrainian management to 
quickly navigate the constantly changing economic environment and get significant benefits from trading with new partners, giving preference to the old ones. As a result, Ukraine loses significant export benefits.

To improve this situation, it is necessary to train to increase the level of cross-cultural management of the companies and management of the foreign economic activity. This will help lower cultural barriers and, consequently, the level of fractality of markets, which will increase the efficiency of export trade. As for the knowledge of the language, as practice shows, the majority of foreign economic activity managers in Ukraine know English, which significantly reduces the level of linguistic barriers in the export deliveries.

\section{References}

[1] H.E. Hurst, International Association of Scientific Hydrology. Bulletin 1, 13 (1956), https://doi .org/10.1080/02626665609493644

[2] B. Mandelbrot, R.L. Hudson, The (Mis)Behaviour Of Markets : A Fractal View of Risk, Ruin, and Reward (Profile Books, London, 2004)

[3] E.E. Peters, Chaos and order in the capital markets: a new view of cycles, prices, and market volatility, 2nd edn. (Wiley, New York, 1996), ISBN 978-0-47113938-6

[4] United Nations, Comtrade database (2020), https: //comtrade.un.org/

[5] E.E. Peters, Fractal market analysis: applying chaos theory to investment and economics (Wiley, Chichester, 1994), ISBN 978-0-471-58524-4

[6] T. Ikeda, Economics Bulletin 37, 1514 (2017)

[7] R.F. Mulligan, The Quarterly Review of Economics and Finance 44, 155 (2004)

[8] N. Maksyshko, O. Vasylieva, CEUR Workshop Proceedings 2422, 467 (2019)

[9] H. Danylchuk, O. Kovtun, L. Kibalnyk, O. Sysoiev, E3S Web of Conferences 166 (2020)

[10] A. Matviychuk, O. Novoseletskyy, S. Vashchaiev, H. Velykoivanenko, I. Zubenko, CEUR Workshop Proceedings 2422, 455 (2019)
[11] H. Danylchuk, L. Kibalnyk, O. Kovtun, A. Kiv, O. Pursky, G. Berezhna, CEUR Workshop Proceedings 2713, 352 (2020)

[12] N. Maksyshko, O. Vasylieva, I. Kozin, V. Perepelitsa, CEUR Workshop Proceedings 2713, 219 (2020)

[13] A. Bielinskyi, S. Semerikov, O. Serdyuk, V. Solovieva, V. Soloviev, L. Pichl, CEUR Workshop Proceedings 2713, 372 (2020)

[14] A. Bielinskyi, I. Khvostina, A. Mamanazarov, A. Matviychuk, S. Semerikov, O. Serdyuk, V. Solovieva, V. Soloviev, IOP Conference Series: Earth and Environmental Science 628 (2021)

[15] M. Frezza, S. Bianchi, A. Pianese, Finance Research Letters 38, 101851 (2021)

[16] M. Karpiarz, P. Fronczak, A. Fronczak, Physical Review Letters 113, 248701 (2014)

[17] J. Tinbergen, The International Executive 5, 27 (1963)

[18] DataBank (2021), https://databank. worldbank. org/indicator/NY.GDP. MKTP. $\mathrm{CD} / 1 \mathrm{ff} 4 \mathrm{a} 498 /$ Popular-Indicators

[19] Distance calculator (2021), https://www. distance.to/

[20] H. Insights, Hofstede insights organisational culture consulting (2021), https: //www.hofstede-insights.com

[21] S.H. Schwartz, The 7 schwartz cultural value orientation scores for 80 countries (2008), 10.13140/ RG . 2.1.3313.3040

[22] L. Vlasenko, Problemy systemnoho pidkhodu v ekonomitsi 1 (2017)

[23] EF English Proficiency Index https://www.ef.com/assetscdn/ WIBIwq6RdJvcD9bc8RMd/legacy/__/ / media/centralefcom/epi/downloads/ full-reports/v10/ef-epi-2020-russian. pdf

[24] Ethnologue: Languages of the World (2021), https://www.ethnologue.com 